Article

\title{
Disclosure Style and Its Determinants in Integrated Reports
}

\author{
Aureliana-Geta Roman ${ }^{1}$, Mihaela Mocanu ${ }^{1, *}$ and Răzvan Hoinaru ${ }^{2}$ \\ 1 Department of Accounting and Auditing, Bucharest University of Economic Studies, \\ 010374 Bucharest, Romania; romanaureliana@yahoo.de \\ 2 School of Business and Management, Queen Mary, University of London (QMUL), London E1 4NS, UK; \\ hoinarur@yahoo.com \\ * Correspondence: mihaela.mocanu@cig.ase.ro
}

Received: 25 February 2019; Accepted: 31 March 2019; Published: 2 April 2019

check for updates

\begin{abstract}
Integrated Reporting promotes a more cohesive and efficient approach to corporate reporting and aims to improve the quality of information available to providers of financial capital. The purpose of this paper was to investigate the determinants of readability and optimism which build the disclosure style of integrated reports. Our research draws on impression management theory and legitimacy theory, while also taking into consideration the cultural system of Hofstede with its further developments by Gray. Our sample consisted of 30 annual reports, extracted randomly from the Integrated Reporting examples database set up by the International Integrated Reporting Council. For the purposes of our investigation, we have carried out a multivariate regression analysis. Firstly, our results show that the higher the revenues of the reporting company, the more balanced their integrated reports, while younger companies use a more optimistic tone when reporting. Additionally, optimism seems to be inversely correlated with the length of the reports. Secondly, entities based in countries with a stronger tendency towards transparency surprisingly provide less readable integrated reports. It was also revealed that companies operating in non-environmentally sensitive industries, as well as International Financial Reporting Standards adopters deliver foggier and thus less readable integrated reports.
\end{abstract}

Keywords: integrated reporting; readability; optimism; disclosure quality; textual analysis

\section{Introduction}

Generally, impression management refers to strategies that people use to create desired social images or identities [1]. Corporate impression management is defined as a discrepancy between a company's substantive actions and the symbolic representations of the substantive actions [2]. Substantive actions lead to real changes in company's operations, whereas symbolic representations are the ways in which the company presents its actions to others. Thus, corporate impression management is the modelling of those representations with the purpose to influence stakeholder perceptions, by controlling what and how is disclosed. Companies have various reasons for using impression management in their reporting instead of actually changing their substantive actions. They are constantly faced with the temptation to adhere only formally to institutionalised rules without putting into practice what they prescribe [3]. Investments are necessary to make changes possible, and it is very likely that such investments have an uncertain return and that they benefit society and not the company. Therefore, previous research suggested that rather than changing their actions, companies find it more convenient and cost-effective to use different impression management tactics. Second, researchers argue that, in many cases, companies can reap the same benefits from impression management efforts 
as from changes in actual behaviour. Thus, there are sufficient incentives for managers to apply impression management tactics.

Impression management is achieved through communications. Most companies are engaged in a variety of forms of communication including not only annual reports, but also press releases, interviews to press, radio and television, promotional videos etc. Annual reports are particularly important in the context of impression management, because they are in fact written self-descriptions of companies and their operations, based on which organisations are able to create their desired identity. Therefore, these reports may be seen by definition as instruments of impression management [4]. Generally, annual reports could be considered "a window onto the use of communication strategies" of senior executives [5], because they are used to account for what the organisation has done. In recent times, corporate reporting has been increasingly used to celebrate achievements in order to present favourable images of the corporation and thereby enhance the perception upon the legitimacy of its activities [6]. If companies are perceived to be legitimate, they will find it easier to attract economic resources and gain the social and political support necessary for successfully continuing their operations.

Maintaining and repairing the company's legitimacy among stakeholders can be achieved, among other means, through integrated reporting [7]. Companies need legitimacy to survive and an important vehicle to demonstrate legitimacy is the reporting of financial and non-financial matters [8]. Legitimacy is defined as a generalised perception or assumption that the actions of an entity are desirable or appropriate within some socially constructed systems of norms, values, beliefs and definitions [9]. Legitimacy has been debated by institutional theorists, who intended to clarify how firms respond to their surrounding environments. Organisations are expected to observe the institutional norms and rules that prevail in their operating environment. As a result, their compliance with the formal regulations will earn them legitimacy among stakeholders. This is particularly important since stakeholders, including governments, regulatory authorities, non-governmental organisations and others, can exert their influence on businesses [10]. Although legitimacy may be possessed objectively, it is created subjectively. Company managers may be well aware of the information asymmetry between company and stakeholders and may exploit it in their corporate disclosures, thus exhibiting an opportunistic behaviour [11].

Moreover, legitimacy refers to cultural and constitutive beliefs [9]. Culture establishes how the company develops, how it should behave and how the public assesses and interprets its economic and social performance [12]. An organisation's activities are consistent and accommodated by cultural models which provide a basis for the existence of the firm [13]. Culture describes a system of societal or collectively held values, whereas values are "a broad tendency to prefer certain states of affaires over others" [14]. Geert Hofstede and his research team argued that world cultures vary along four consistent dimensions: power distance, individualism versus collectivism, femininity versus masculinity and uncertainty avoidance. This work was carried forward at the level of accounting subculture by Gray, who identified four accounting-related cultural values: professionalism versus statutory control; uniformity versus flexibility; conservatism versus optimism; and secrecy versus transparency [15]. Scholars have shown that companies operating in countries with similar national cultural systems adopt homogeneous patterns regarding integrated reporting (IR) adoption [16]. Additionally, they suggested that companies located in societies with stronger collectivist and feminist values are in the vanguard of information integration. Thus, the cultural system may play an important role in corporate disclosure practices in general and in integrated reporting practices of companies, in particular.

Our research draws on impression management theory and legitimacy theory, while also taking into consideration the cultural system of Hofstede with its further developments by Gray, in order to shed light upon world-wide best practices in integrated reporting. The concept of "integrated reporting" (IR) has been gaining prominence during the past decade. In its simplest form, integrated reporting can be understood as the convergence of the sustainability report and the financial report into a single narrative [17]. Sustainability is three-dimensional and links three areas: ecology/environment, 
economy/profit and social/people [18]. The integrated report is mainly intended for investors and discloses not only financial, but also non-financial aspects, namely the top management's views on how sustainability issues and initiatives contribute to the long-term growth strategy of the business. Research shows that non-financial reporting has a pivotal role in the investment decisions for a greater percentage of the investors than in previous years [19-22]. Integrated reporting has been promoted recently as a solution to the shortcomings of financial reporting [23]. The International Integrated Reporting Council (IIRC) has been making continuous efforts to advocate integrated reporting as a holistic and integrated representation of the company's performance in terms of both its finances and its sustainability. The aim of the current IIRC framework is to "improve the quality of information available to providers of financial capital to enable a more efficient and productive allocation of capital". IIRC states that the demand for IR stems from the need of investors to understand how the strategy being pursued creates value over time.

Academia shows more and more interest in integrated reporting and both leading accounting conferences and highly ranked journals have recently started to publish research papers on the IR topic. However, much IR research is still in its first stage when efforts are directed towards raising awareness of the research field's potential [24]. Currently, there are studies on the topic, some of which developed a critical position towards integrated reporting [25-28]. On the contrary, other studies have indicated the potential usefulness of integrated reporting $[17,29,30]$. Some recent academic papers provide a comprehensive overview of the development of IR and associated literature [24,31,32]. Overall, there is a lack of studies on the quality of the disclosure produced in integrated reports, except for a few papers [33-36].

Our research contributes to the growing body of literature on integrated reporting. The objective of our study is to investigate the determinants of the style of disclosure in integrated reports which are considered "leading practices" by the IIRC. In our view, gaining additional knowledge about the "leading practices" in integrated reporting can benefit not only the practitioners, but also businesses and academia. Our contribution to the literature is significant due to our innovative research approach. To the best of our knowledge, only one other study [33] applied textual analysis tools to shed light upon the disclosure quality of integrated reporting. The paper is structured as follows. First, we perform a review of the most relevant studies published on the topic of integrated reporting. Secondly, we thoroughly describe the reasoning that led us to the research hypotheses to be developed. Thirdly, the research design is described in the detail. The last two sections of the paper are destined to describe the results and discuss them in light of prior studies.

\section{Literature Review}

The International Integrated Reporting Council recently developed a non-mandatory Framework meant to accelerate the adoption of integrated reporting world-wide [23]. The IIRC's long term vision consists in making Integrated Reporting the corporate reporting norm. An integrated report is defined as "a concise communication about how an organisation's strategy, governance, performance and prospects, in the context of its external environment, lead to the creation of value over the short, medium and long term." Integrated reporting (IR) combines both financial and nonfinancial disclosures of a company's performance. Regarding the integrated reporting process, a salient feature is integrated thinking, defined as "the active consideration by an organisation of the relationships between its various operating and financial units and the capitals that the organisation uses or affects" [23]. Thus, an Integrated Report encourages companies to think about how they generate value. In contrast with stand-alone sustainability reports, IR is able to effectively communicate a company's business model, may include all sources of value creation and is appropriate for taking account of the complex interconnections between sustainability and financial performance [33,37]. Through integrated reporting, organisations demonstrate their responsibility towards the global economy and the three major stakeholders: shareholders, society and the environment [38]. 
Thus, by definition, integrated reports contain both mandatory as well as voluntary corporate disclosures. Mandatory disclosures are derived from accounting standards which are mainly targeted towards protecting the interests of shareholders with a direct financial interest in organisations. However, in all organisations, there are other stakeholders who have an equitable interest in them, even though such stakeholders do not own any equity. The management is discretionary when making voluntary disclosures to meet the needs of those interested parties [39]; however, these voluntary disclosures are a trade-off between the need of fairly treating these stakeholders and an equally important need of withholding information to ensure organisational survival and growth $[40,41]$. The suitability of voluntary disclosure is decided by the intentions of the board of directors [42], who determine strategically which disclosures are adequate to stakeholders and faithfully represent organisational activities, rather than making disclosures neutrally based on a set of rules [43].

Integrated reporting has recently received significant attention from the academia. As any other emerging research field, integrated reporting has raised concerns, controversies and critique. Some argued that IIRC's framework does not address the decision-making needs of stakeholders (other than investors), because it is focused on the information demands of capital providers only [26]. Similarly, other researchers [27] contended that the close connections between the report preparers and the investors can limit the IR potential to help other stakeholders to better understand the non-financial impacts of the reporting organisation. Some [28] argued that there is a significant gap between the information that is supplied by disclosing companies and the information that is sought by the financial markets. In [25], it was pointed out that the IIRC's governing council is dominated by the accountancy profession and multinational enterprises, which feel that this IR initiative threatens their established position, following that the IIRC's proposals will have little impact on corporate reporting practice. In this sense, an IR implementation feedback of the framework reads that there is general support from a multi-capital approach; however, for the time being, there is a problem of connectivity in between data and variables that does not fully allow integrated thinking. Therefore, better collaboration with third parties is encouraged, as academic research discovered. This lack of materiality for some society at large may happen due to lack of practical examples of meaning and use, especially as there is a departure from traditional sustainability reporting and increased complexity of financial disclosure towards more advanced forms of reporting that needs to have a better integration [44].

On the contrary, other studies have indicated the potential usefulness of integrated reporting. For instance, [17] provide suggestive evidence of a positive relationship between effective management of environmental, social and governance (ESG) issues and integrated reporting. Thus, companies that proactively manage the risks and opportunities arising from ESG matters are also more likely to communicate on sustainability issues in an integrated way. Research concludes that firms that practice more IR have a more long-term investor base and that this result is driven by having more dedicated and fewer transient investors [29]. Moreover, the adoption of IR leads to changes in a firm's investor base, although the reverse is not happening. On a related note, it was found [30] that the improvement in the level of alignment of integrated reports with the IR framework is associated with a subsequent reduction in the cost of equity capital and the realized market returns, which is consistent with the notion that investors are willing to accept a lower rate of return as a result of reduced information risk.

A number of recent academic papers provide a comprehensive overview of the development of IR and associated literature [24,31,32]. A very informative and systematic literature review noted that most articles adopt a general approach to IR, while only a few articles analyse specific organisations [24]. Publicly listed companies are the most commonly researched organisations. Regarding the country of research, the European Union is the most active region, followed by Australasia. South Africa is not at the IR research forefront as expected, even though it is a pioneering country of IR and the only country that currently requires publicly listed companies to issue an integrated report on an "apply or explain" basis. Moreover, [24] find that the focus of literature in the field of IR lies on external reporting, which is expected because the IR Framework states, "the primary purpose of an integrated report is to explain to providers of financial capital how an organization creates value over time". 
IIRC produced a study called "Achieving balance in the integrated report", which, even though it is centred on a certain geographical space, provides useful information in general. The report mainly concludes that: "The level of trust between organizations, either public or private, and their stakeholders may well be at one of its low points in history. The pervasive call for transparent, credible and quality reporting, as a critical component of accountability and stakeholder engagement, is timely and vital to rebuilding trust" [45].

Taking into account prior research, our study focused on the quality of IR and its determinants. Few papers have had a similar approach. For example, [46] and [47] provide evidence of a positive link between IR quality and market reactions for IR adopters in South Africa. In the Czech Republic, [48] found that non-financial reporting is weakly positively linked with the size and age of the company, and it is weakly negatively associated with company indebtedness. At the same time, the non-financial reporting measures are independent on profitability indicators (such as return on equity and return on assets). However, the current measurement of IR quality remains highly questionable. Overall, there is a lack of studies on the quality of the disclosure produced in integrated reports, except for a few studies [47-50]. Our research aimed to fill in this literature gap regarding IR quality and perform a textual analysis of a sample of voluntary integrated reports. In some prior studies, disclosure quality was inferred by lexical characteristics such as readability [51,52] and tone [49]. We followed a similar approach, as described in the next section.

\section{Development of Hypotheses}

According to the International Integrated Reporting Framework (IIRF), the guiding principles in drafting an integrated report are: (a) strategic focus and future orientation; (b) connectivity of information; (c) stakeholder relationships; (d) materiality; (e) conciseness; (f) reliability and completeness; and (g) consistency and comparability. First of all, our research focused on the principle of conciseness, which is believed to assist in reducing the reporting burden for organisations ([6], paragraphs 3.36-3.38). As mentioned in the International Integrated Reporting Framework, a concise integrated report is characterized by clarity in the expression of concepts, usage of as few words as possible, limited use of technical terms and avoidance of highly generic disclosures. Researchers [33] found that the emphasis on conciseness is innovative, on the background of prior attempts to enhance the disclosure quality of narrative disclosures on financial and nonfinancial matters.

Second of all, we focused on the principle of reliability. More precisely, we intended to investigate the balance of integrated reports, an attribute which contributes to their reliability. As explained in the IIRF, a balanced integrated report has no bias in the selection or presentation of information. To attain balance, reporting entities should give equal consideration to both increases and decreases in the capitals, strengths and weaknesses of the organisation, positive and negative performance, etc. ([23], paragraphs 3.44-3.45). Balance is a matter closely related to the extent in which companies make use of impression management methods in order to distort audience perceptions on their image [50].

Conciseness and balance build the style of disclosure, understood as syntactical reading ease and verbal tone manipulation [33]. In line with the impression management literature, we argue that the levels of balance in integrated reports vary systematically depending on corporate performance. We drew on prior research [53-56] and expected that companies with low levels of performance use a more optimistic tone (i.e., are less balanced) in order to improve the image resulting from their integrated reports. On the contrary, managers of high-performing companies have no incentive to deliberately mislead communication.

Additionally, in line with the legitimacy theory, a company's public reputation is determined by how much time that company has been operating. Building a reputation requires consistency in behaviour within the company, as well as consistency in disclosure through time. Specific disclosure actions are taken by companies not because such disclosures directly communicate information to stakeholders, but mostly because they may enhance or impair their reputation [57]. As [58] point out, it is expected that the longer an entity has been established, the higher its reputation level may 
be. In other words, higher levels of disclosure are expected to build and sustain reputation. Hence, we posit that the integrated reports of older companies are less balanced and disclose on a more optimistic tone compared to the recently established companies.

H1A. Companies with weaker financial performance display a higher level of optimism in IR reports.

H1B. Integrated reports of older companies have a more optimistic tone.

Regarding conciseness, we posit that the differing traits that build up the profile of disclosing companies are the ones influencing the readability level of integrated reports. First, we considered the role of culture in impacting readability. Culture describes a system of societal or collectively held values, whereas values are "a broad tendency to prefer certain states of affaires over others" [29]. The role of culture in influencing and explaining behaviour in social systems has been acknowledged and explored in various fields, such as anthropology, sociology and psychology. A framework for the comparison of different cultures was developed by Hofstede and his research team and was expanded by other studies [30] to fit the accounting subculture. The following cultural dimensions are in place: Professionalism versus Statutory Control, Uniformity versus Flexibility, Conservatism versus Optimism, and Secrecy versus Transparency. Particularly relevant for the present research is secrecy, described as confidentiality and restricted disclosure of information about the business. Thus, we expected that the higher the tendency towards secrecy in the country where the reporting company is based, the lower the readability of IR reports and vice versa.

Secondly, we argue that publicly listed companies are more likely to provide more readable integrated reports, since the provided information is destined to a higher number of interested parties-not only management and creditors, but also current and potential investors. In other words, publicly visible organisations are exposed to greater demands from a greater variety of relevant external actors. Publicly listed companies may also be in the position to exert a higher degree of influence, control or power over the resource environment. To enhance their corporate reputation, they strategically control through disclosure the legitimation process, in order to influence stakeholders' perceptions of themselves and in order to control resources flow [59].

H2A. Firms based in countries with a higher tendency towards secrecy provide less readable IR reports.

H2B. Publicly listed companies provide more readable integrated reports.

\section{Research Design}

The International Integrated Reporting Council ('the IIRC') created and promoted a database with reports which can be used as a reference point for integrated reporting. Our sample consists of 30 such annual integrated reports, extracted randomly from the Integrated Reporting examples database set up by IIRC. Thus, the main source of data was the information voluntarily made available by companies in these integrated reports. The reports refer to the financial year 2017 and belong to companies operating in different industry groups. Most of the selected companies are based in South Africa (11 organisations) and United Kingdom (nine organisations), while the others operate in the following countries: Australia, Brazil, Italy, Japan, Luxembourg, Netherlands, New Zealand, Singapore and Sri Lanka. Table 1 provides sample demographics distinguishing between different industries, while Table 2 provides sample demographics that ranks selected companies based on their revenues for the year 2017. 
Table 1. Sample demographics by industry.

\begin{tabular}{cc}
\hline Industry Name & Percent \\
\hline Oil and gas & 3.33 \\
Basic materials & 3.33 \\
Industrials & 13.33 \\
Healthcare & 13.33 \\
Consumer services & 10.00 \\
Telecommunications & 3.33 \\
Utilities & 6.67 \\
Financial services & 36.67 \\
Professional services & 3.33 \\
Public sector & 3.33 \\
Real estate & 3.33 \\
TOTAL & $\mathbf{1 0 0 . 0 0}$ \\
\hline
\end{tabular}

Table 2. Sample demographics by revenues in thousand euro (TEUR).

\begin{tabular}{cc}
\hline Revenues & Percent \\
\hline Below 1,000,000 TEUR & 23.33 \\
1,000,000-4,000,000 TEUR & 30.00 \\
4,000,000-10,000,000 TEUR & 16.67 \\
10,000,000-30,000,000 TEUR & 13.33 \\
More than 30,000,000 TEUR & 16.67 \\
\hline TOTAL & $\mathbf{1 0 0}$ \\
\hline
\end{tabular}

In selecting our sample we made sure to include big companies, whereas the level of the revenues was a proxy for their size. The reason behind this choice is that previous research suggests there is an influence of the size over the quality and quantity of corporate disclosure. Linsley, Shrives and Crumpton [60] analysed the contents of the annual reports of nine banks from the United Kingdom and nine Canadian banks in 2001 and found that the extent of risk disclosure is positively associated with bank size. By means of a multivariate regression analysis, Hossain and Reaz [61], as well as Sanchez-Ballesta and Bernal Llorens [62], discovered a positive and statistically significant relation between size as explanatory variable and corporate disclosures as dependent variable. This may be explained by the fact that the cost of collecting and disseminating information is lower for larger institutions, and thus, are able to provide greater and/or better disclosure.

We investigated two dependent variables: readability and optimistic tone of IR reports. First of all, the readability of the selected reports was measured by using an index derived from the computational linguistics literature-respectively the Gunning Fog index. This index has been previously used by researchers to measure the readability of corporate narrative disclosures [51,52]. For the purpose of avoiding any subjectivity in computing the Gunning Fog index, the authors have scanned each of the sampled integrated reports through a readability online application.

The Gunning Fog index is calculated according to the following formula: Fog $=$ (words_per_sentence + percent_of_complex_words)/0.4. The assumption behind this formula is that more words per sentence or more syllables per word make a document more difficult to read. Complex words are considered to be words with three syllables or more. The index shows the number of years of formal education a reader of average intelligence would need to read the text once and understand that piece of writing with its word-sentence workload. In particular, the relation between the Fog and reading ease is as follows: Fog $\geq 18$ (unreadable); 14-18 (difficult); 12-14 (ideal); 10-12 (acceptable); and 8-10 (childish).

Second of all, according to the IIRC, integrated reports should be balanced, in other words, they should not have any bias in the presentation of information to change the probability that it will be received either favourably or unfavourably. To capture this aspect, we performed a textual analysis 
with the help of the application LIWC2015. The application relies on an internal default dictionary that defines which words should be counted in the target text files. Each word is assigned to specific linguistic categories, and the percentage of total words in each category is reported. For example, the word cried falls into four categories: sadness, negative emotion, overall affect and past-tense verb. Our analysis focused on four linguistic indicators from the category "drives": achievement, power, reward and risk. Table 3 displays examples of words in the categories relevant for our research.

Table 3. LIWC2015 Output Variable Information for the overall category "drives".

\begin{tabular}{ccc}
\hline Category & Examples & Words in Category \\
\hline Achievement & win, success, better & 213 \\
Power & superior, bully & 518 \\
Reward & take, prize, benefit & 120 \\
Risk & danger, doubt & 103 \\
\hline
\end{tabular}

Source: LIWC2015 Development Manual.

For the purpose of measuring the balance of an IR report, we used a self-computed optimism index, based on the formula: Optimism $=$ [achievement + power + reward $]-$ risk. Words emphasizing the company's successful status increase the optimism of disclosure, while words that underline the risks faced by the disclosing company diminish the report's optimistic tone. This score emphasizes the optimism versus pessimism of disclosure, i.e., the higher the score, the more the text is skewed towards an optimistic tone, whereas the lower the score, the more balanced the extent of positive and negative language used in the text. We chose to develop our own score, so that we can align this score in the best possible manner to our specific research objectives. The LIWC2015 "emotional tone" is computed based on the research of [63], who investigates language use for a period of 2 months prior to and after the September 11 attacks with the purpose of highlighting psychological changes in response to the attacks. The "emotional tone" thus measured may not be appropriate in the context of corporate financial disclosures, which usually narrate on past events (such as achievements or failures) or prospective events (such as opportunities or risks) and are less likely to contain emotional reactions to such events.

We performed a multivariate regression analysis for each of the dependent variables-readability and optimistic tone of IR reports. In order to investigate the determinants of readability of integrated reports, we considered a set of explanatory variables that characterize the disclosing companies: whether the company's country of origin is culturally inclined towards secrecy; whether the company is publicly listed (independent variables); whether the company adopts the international financial reporting standards; the industry to which the company belongs to; the continent where the company's headquarters are based; and whether the civil law prevails (control variables). In order to investigate the determinants of the optimism of integrated reports, we chose as independent variables the revenues disclosed in the statement of comprehensive income and the company's age, and as control variables-the continent where the company's headquarters are based; the industry to which the company belongs to; and the length of the IR report. All variables used, their definitions and measures are presented in Tables 4 and 5.

Previous impression management studies consider industry as control variables influencing disclosure choices. Specifically, belonging to environmental sensitive industry groups could favour the adoption of impression management strategies. Companies that belong to industries in which the processes put greater stress on the natural environment are subject to more public pressure. Such companies belonging to environmentally sensitive industries have greater incentives to manipulate the disclosure offered in their corporate reports. Therefore, in line with [50], we include a dummy that is equal to 1 (one) if companies belong to a non-environmentally sensitive industry (Consumer Goods; Consumer Service; Healthcare; Technology; Telecommunication; Financials industry; Professional services; Real estate) and 0 (zero) if they belong to an environmentally sensitive industry (Oil and Gas, Basic Materials, Industrials, Utilities, Public Sector). 
Table 4. Variables definition and measurement (model A).

\begin{tabular}{|c|c|c|}
\hline Variable Acronym & Variable Definition & Measurement \\
\hline \multicolumn{3}{|l|}{ Dependent } \\
\hline \multicolumn{3}{|l|}{ Readability } \\
\hline Fog & Fog readability & (words_per_sentence + percent_of_complex_words) ${ }^{*} 0.4$ \\
\hline Independent & & \\
\hline Secrecy & Secrecy & Transparent (=0); Neuter $(=1)$; Secret-prone $(=2)$ \\
\hline Listing & Listing status & Listed company $(=1)$; Non-listed company $(=0)$ \\
\hline \multicolumn{3}{|r|}{ 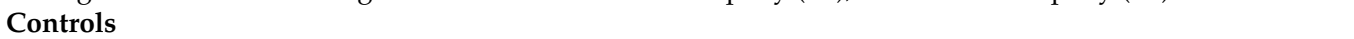 } \\
\hline IFRS & IFRS adopter & $\begin{array}{l}\text { Dummy variable equals to } 1 \text { if the firm adopts the } \\
\text { International Financial Reporting Standards (IFRS) and } 0 \\
\text { otherwise }\end{array}$ \\
\hline Continent & Continent & $\begin{array}{l}\text { Continent dummies: Africa }(=0) \text {; Europe }(=1) \text {; Asia and } \\
\text { Australia }(=2) \text {; North America and South America }(=3)\end{array}$ \\
\hline Law & Type of law & Civil law (=1); Common law (=0) \\
\hline Industry & Industry & $\begin{array}{l}\text { Consumer Goods; Consumer Service; Healthcare; Technology; } \\
\text { Telecommunication; Financials industry; Professional services; } \\
\text { Real estate }(=1) \text {; Oil and Gas, Basic Materials, Industrials, } \\
\text { Utilities, Public Sector }(=0)\end{array}$ \\
\hline
\end{tabular}

Table 5. Variables definition and measurement (model B).

\begin{tabular}{|c|c|c|}
\hline Variable Acronym & Variable Definition & Measurement \\
\hline \multicolumn{3}{|l|}{$\begin{array}{l}\text { Dependent } \\
\text { Optimistic tone }\end{array}$} \\
\hline Optimism & Optimism Index & $\begin{array}{l}\text { [achievement }+ \text { power }+ \text { reward] - risk, whereas word count } \\
\text { for each category is an output of LIWC2015 }\end{array}$ \\
\hline \multicolumn{3}{|l|}{ Independent } \\
\hline revenues_n & $\begin{array}{l}\text { Revenues as a } \\
\text { measure of financial } \\
\text { performance }\end{array}$ & $\begin{array}{l}\text { Total revenues translated into Euro at the exchange rates } \\
\text { disclosed by national banks as at } 31 \text { December } 2017 \\
\text { (normalized) }\end{array}$ \\
\hline $\begin{array}{l}\text { Age } \\
\text { Controls }\end{array}$ & Age of the firm & Number of years since commencement of operations \\
\hline Continent & Continent & $\begin{array}{l}\text { Continent dummies: Africa }(=0) \text {; Europe }(=1) \text {; Asia and } \\
\text { Australia }(=2) \text {; North America and South America }(=3) \\
\text { Consumer Goods; Consumer Service; Healthcare; Technology; }\end{array}$ \\
\hline Industry & Industry & $\begin{array}{l}\text { Telecommunication; Financials industry; Professional services; } \\
\text { Real estate }(=1) \text {; Oil and Gas, Basic Materials, Industrials, } \\
\text { Utilities, Public Sector }(=0)\end{array}$ \\
\hline ln_length & Length of the report & $\begin{array}{l}\text { Number of words of the integrated reports, as resulting from } \\
\text { the LIWC2015 output (normalized) }\end{array}$ \\
\hline
\end{tabular}

Among the traits that portray a company, and thus influence their disclosure style, we also included the company's continent, in line with previous cross-country studies on corporate disclosure [64]. However, accounting standards vary significantly within the regions. Thus, following a similar approach as [33], when investigating readability, we also controlled for the accounting regulatory framework used by the selected companies by including a dummy variable that is equal to 1 if firms adopt International Financial Reporting Standards (IFRS) and 0 otherwise. Additionally, we took into consideration as control variable for reports' readability the country's legal system, considering that studies showed that companies located in civil law countries are more likely to create and publish a broad range of integrated reports, thus favouring decision-taking by the different stakeholders [65]. With regard to the optimism level of integrated reports, we found it appropriate to also control for the length of the reports, measured as the natural logarithm of the number of words in the analysed documents.

\section{Results}

The means, standard deviations, minimum and maximum of the continuous variables are presented in Table 6. With reference to the length of the selected integrated reports, the results show that their length was on average 75,414 words, with a maximum of 204,248 and a minimum of 
16,686 words. In Table 6, we present the variable transformed through natural logarithm. The textual analysis reveals that the mean of the Gunning Fog index is equal to 10.9500, suggesting that the reports, on average, were neither difficult, nor childish, but could be characterized as "acceptable" from the viewpoint of readability. The descriptive statistics for the categorical variables is presented in Table 7. The frequencies show that the majority of the companies in the sample were listed and have adopted the International Financial Reporting Standards. Additionally, more than two thirds of the companies are operating in a non-environmental sensitive industry such as consumer goods and service, healthcare, technology, telecommunication, financials, professional services or real estate. Most of the companies are based in Africa and Europe and operate under common law.

Table 6. Descriptive statistics for continuous variables.

\begin{tabular}{ccccc}
\hline & Mean & Std. dev. & Min & Max \\
\hline age & 85.6000 & 123.7390 & 11.0000 & 681.0000 \\
ln_length & 11.0100 & 0.6978 & 9.7200 & 12.2300 \\
revenues_n & 0.1579 & 0.2447 & 0.0000 & 1.0000 \\
optimism & 6.9720 & 1.2285 & 4.6100 & 10.2500 \\
fog & 10.9500 & 1.0615 & 8.9000 & 12.7000 \\
\hline
\end{tabular}

Table 7. Descriptive statistics for categorical variables.

\begin{tabular}{|c|c|c|}
\hline Secrecy & $N$ & $\%$ \\
\hline Transparent $(=0)$ & 22 & $73 \%$ \\
\hline Neuter $(=1)$ & 6 & $20 \%$ \\
\hline Secret-prone (=2) & 2 & $7 \%$ \\
\hline Total & 30 & $100 \%$ \\
\hline Listing & $N$ & $\%$ \\
\hline Listed company $(=1)$ & 27 & $90 \%$ \\
\hline Non-listed company $(=0)$ & 3 & $10 \%$ \\
\hline Total & 30 & $100 \%$ \\
\hline IFRS & $N$ & $\%$ \\
\hline IFRS adopter $(=1)$ & 25 & $83 \%$ \\
\hline Not IFRS adopter $(=0)$ & 5 & $17 \%$ \\
\hline Total & 30 & $100 \%$ \\
\hline Continent & $N$ & $\%$ \\
\hline Africa $(=0)$; & 12 & $40 \%$ \\
\hline Europe $(=1)$ & 13 & $43 \%$ \\
\hline Asia and Australia (=2); & 4 & $13 \%$ \\
\hline $\begin{array}{c}\text { North America and South } \\
\text { America }(=3)\end{array}$ & 1 & $3 \%$ \\
\hline Total & 30 & $100 \%$ \\
\hline Law & $N$ & $\%$ \\
\hline Civil law (=1) & 6 & $20 \%$ \\
\hline Common law $(=0)$ & 24 & $80 \%$ \\
\hline Total & 30 & $100 \%$ \\
\hline Industry & $N$ & $\%$ \\
\hline $\begin{array}{c}\text { Non-environmental sensitive } \\
\text { industry }(=1)\end{array}$ & 21 & $70 \%$ \\
\hline $\begin{array}{l}\text { Environmental sensitive industry } \\
\qquad(=0)\end{array}$ & 9 & $30 \%$ \\
\hline Total & 30 & $100 \%$ \\
\hline
\end{tabular}


Regarding the tendency towards secrecy from within their cultural environment, $73 \%$ of the countries of origin can be considered "transparent", $20 \%$ neuter and $7 \%$ inclined to secrecy. Companies have been included into one of these three categories based on the hypothesis of Gray [15], which in their turn, are derived from the cultural framework developed by Hofstede: the higher a country ranks in terms of uncertainty avoidance and power distance and the lower it ranks in terms of individualism and masculinity, the more likely it is to rank highly in terms of secrecy. Gray [15] contrasted secrecy with transparency: one pole is the confidentiality and restricted disclosure of information about the business to those who are closely involved with its management and financing and the other pole is transparency, openness and accountability towards the public a preference for secrecy. Generally, such a predilection is consistent with strong uncertainty avoidance, high power distance, collectivism and femininity.

In order to incorporate categorical variables with more than two values into the multivariate regression analysis, dummy coding was a necessary process. Thus, we have created dichotomous variables for the categorical variables "secrecy" and "continent".

The regression models that we have tested have the following general form:

Model A: fog $=\alpha_{0}+\alpha_{1} \cdot$ neutrality $+\alpha_{2} \cdot$ transparency $+\alpha_{3} \cdot$ listing + controlvariables $+\varepsilon_{t}$

Model B: optimism $=\beta_{0}+\beta_{1} \cdot$ revenues_n $+\beta_{2} \cdot$ age + control variables $+\varepsilon_{t}$

Their expanded form reads as follows:

Model A: fog $=\alpha_{0}+\alpha_{1} \cdot$ neutrality $+\alpha_{2}$.transparency $+\alpha_{3}$. listing $+\alpha_{4} \cdot$ ifrs $+\alpha_{5}$. europe + $\alpha_{6} \cdot$ australasia $+\alpha_{7} \cdot$ africa $+\alpha_{8} \cdot$ law $+\alpha_{9} \cdot$ industry $+\varepsilon_{\mathrm{t}}$

Model B: optimism $=\beta_{0}+\beta_{1} \cdot$ revenues_n $+\beta_{2} \cdot$ age $+\beta_{3}$.europe $+\beta_{4} \cdot$ australasia $+\beta_{5} \cdot$ africa + $\beta_{6}$. industry $+\beta_{7} \cdot$ ln $\_$length $+\varepsilon_{\mathrm{t}}$

A multivariate linear regression was calculated to predict the readability index based on the culture-determined tendency towards secrecy, neutrality or transparency in the country of origin and on whether the company was publicly listed or not (see Table 8). The regression model A is valid and its parameters are significant $\left(\mathrm{F}(9,20)=2.71, p<0.05\right.$, with an $\mathrm{R}^{2}$ of 0.55$)$. The R-Squared indicates that $55 \%$ of the variation in the Gunning Fog readability index is explained by the two dependent variables, having controlled for various variables, namely: applicable financial reporting framework, continent, law type and industry. Integrated reports' predicted readability index was indeed influenced by the tendency towards transparency in the country where the company is based. If according to the cultural traits, transparency is preferred to secrecy, this contributes to the readability index with 2.0319 more than secretive countries. The average Fog readability index is 10.95 , with a minimum of 8.9 and a maximum of 12.7. However, it appears that the listing status of the reporting company is not a significant predictor of integrated reports' readability. Moreover, if the firm applies IFRS, readability index increases; therefore, the reports are "foggier" and more difficult to read (significant at $10 \%$ level). Belonging to an environmental sensitive industry decreases the readability index with 0.7888 more than being a company that operates in a non-environmental sensitive sector (significant at $10 \%$ level).

A multivariate linear regression was calculated to predict optimism score based on companies' financial performance and age (see Table 9). The regression model B was found valid and its parameters were significant $\left(F(7,22)=2.93, p<0.05\right.$, with an $\mathrm{R}^{2}$ of 0.48$)$. The R-Squared indicates that $48 \%$ of the variation in the optimistic score is explained by the dependent variables, having controlled for continent, industry and report length. Integrated reports' predicted optimism score is equal to 18.4484 -1.7139 (revenues_n) -0.0040 (age) + control variables, where age is expressed in years and revenues were initially measured in thousand euros and afterwards normalized to values ranging from 0 to 1. The optimism score decreased 1.7139 for each increase of revenues and decreased by 0.0040 for each additional year since the inception of the reporting company. The mean optimism score was 6.972, while the minimum was 4.61 and the maximum 10.25. Both revenues and age of the firm were significant predictors of the optimism score. Moreover, results indicate that the longer the integrated report, the less optimistic its tone is (control variable ln_length is significant at $1 \%$ level). Industry and geographical area did not seem to influence the optimism in reporting. 
Table 8. Model A-Readability.

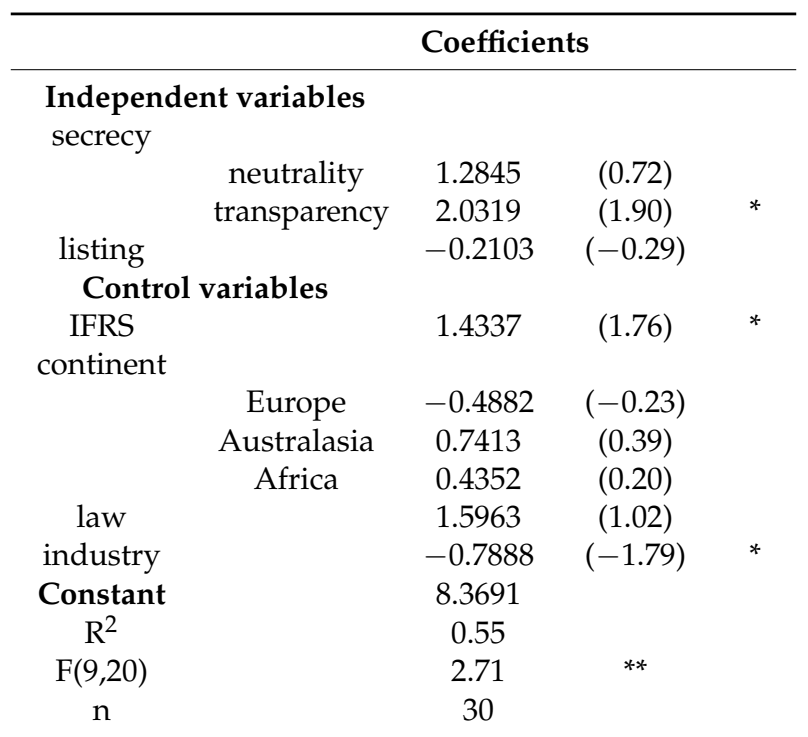

* Statistically significant at $10 \%$ level. ${ }^{* *}$ Statistically significant at $5 \%$ level. ${ }^{* *}$ Statistically significant at $1 \%$ level. T statistics are in brackets.

Table 9. Model B-Optimism.

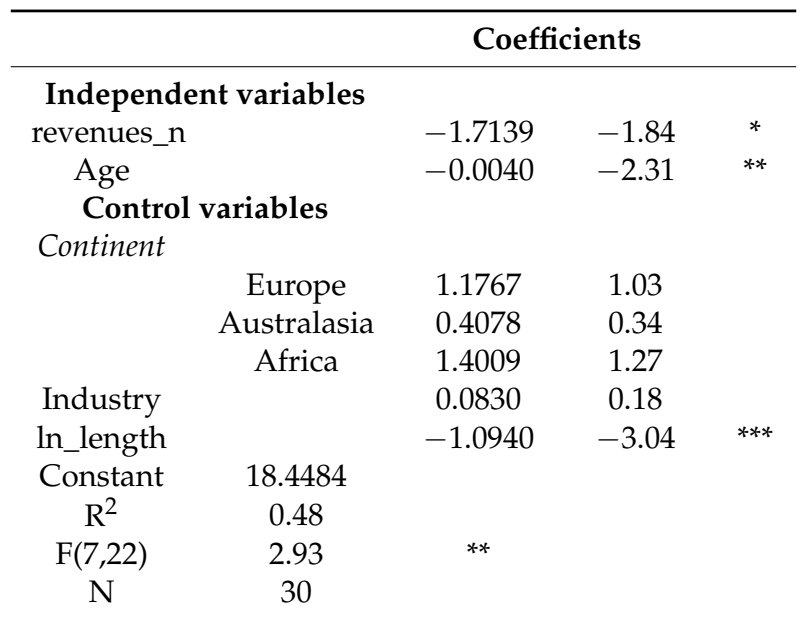

* Statistically significant at $10 \%$ level. ${ }^{* *}$ Statistically significant at $5 \%$ level. ${ }^{* * *}$ Statistically significant at $1 \%$ level. $\mathrm{T}$ statistics are in brackets.

\section{Discussion and Conclusions}

This research contributes to the larger debate on disclosure quality by analysing the lexical features of integrated reports and by aiming to understand its most relevant determinants. The paper adds to the increasing amount of literature that applies textual analysis. This body of research has grown due to the increased online availability of corporate reports and to the improvement of the analytical software tools that can be used to investigate text. We focused on the style of disclosure that characterizes integrated reports, more precisely on readability and optimistic tone. As emphasized by prior contributions, these textual attributes potentially affect the quality of disclosure on environmental, social and governance issues, and are thus likely to be of interest to investors and regulators. Our research draws on impression management theory and legitimacy theory, while also taking into consideration the cultural system of Hofstede with its further developments by Gray. 
Our sample comprised 30 annual integrated reports, extracted randomly from the examples database set up by IIRC. The reports belong to companies from various continents and operating in different industry groups and refer to the most recent financial year, 2017. We have decided upon this sample, since these reports are considered "best practices" and should lead by example with regard to disclosure quality. Our analysis concentrated on the readability and optimistic tone of the narrative integrated reports.

First of all, concerning the relationship between performance and optimism, our findings agreed with the impression management argument empirically confirmed by previous studies from the area of financial and sustainability reporting. According to such studies, firms with lower financial performance tend to produce reports unbalanced towards optimism. For instance, Clarkson et al. ([66]) pointed to the fact that weak performers may try to distract investors from objective measures of performance by using claims to be committed to environmental and social issues. Indeed, our results showed that the higher the revenues of the reporting company, the more balanced their integrated reports-their tone is less optimistic. This might signal a disclosure manipulation strategy where the aim of the companies with worse financial performance is to improve their image and convince the investors or other stakeholders of their success in both financial and non-financial terms, which might actually contradict the reality. Therefore, our hypothesis according to which companies with weaker financial performance display a higher level of optimism in IR reports has been confirmed by the research results. Our findings are in agreement with previous studies. This is in line with Meloni et al. [33], who also found that in the presence of a firm's weak financial performance, the integrated report tends to be significantly longer and less readable.

However, our hypothesis regarding the positive association between age and optimism of disclosure is rejected. On the contrary, our results indicate a significant negative relationship between company's age and balance in integrated reports. In other words, the integrated reports of younger companies are less balanced and use a more optimistic tone compared to companies for which more time elapsed from their establishment. Similar studies did not find any association between age and optimistic tone of integrated reporting [33]. Our results can be explained through a potential disclosure manipulation strategy where recently established companies have a stronger need of consolidating their position in the eyes of stakeholders and of building a good reputation. Additionally, optimism seems to be inversely correlated with the length of the reports, whereas the results show that the longer the disclosure, the more balanced its tone. Concluding, we have empirically found that younger companies with lower financial performance are inclined to provide more optimistic disclosures in their integrated reports, which tend to be shorter.

Second of all, concerning the relationship between secrecy and readability, our hypothesis has not been empirically validated. We posited that firms based in countries with a higher tendency towards secrecy provide less readable IR reports. In terms of Hofstede's cultural dimensions, secrecy is associated with strong uncertainty avoidance and high power distance, while at the same time cultures inclined towards secrecy are collectivist and feminine. Countries with these cultural traits are generally characterized by confidentiality and restricted disclosure of information about the business. The results of the multivariate regression analysis indicate that firms based in countries with a higher tendency towards transparency (and not towards secrecy) provide less readable integrated reports. This might be explained by the fact that when the company's cultural environment is more transparent, the reports it produces are more complex and information-dense, therefore less readable. Readability appears to be also determined by the type of industry. The Gunning Fog index decreases and in other words the readability increases in case of companies operating in non-environmentally sensitive industries compared to companies active in industries such as oil and gas, basic materials, industrials, utilities and public sector. Moreover, it appears that IFRS-adopters deliver foggier integrated reports. However, the results did not validate the expectation that publicly listed companies provide more readable integrated reports. A reason might be that this characteristic is actually not relevant and does not differentiate the entities in the sample, most of which belong to the category of listed companies. 
Finally, a future study could carry out a comparison between companies based in South Africa, where IR has been mandatory since 2011, and other companies from around the globe. Impression management mainly occurs in less regulated narrative disclosures. Such a study could assess whether mandating integrated reporting improves disclosure characteristics, and whether South African companies achieved a better conciseness and balance in reports. This comparison would reveal whether the struggle of firms in providing concise and balanced integrated reports is the result of an on-going learning process or corporate management aims at strategically manipulating stakeholders' opinions and decisions through financial and non-financial disclosures.

Author Contributions: Conceptualization, M.M.; Investigation, A.-G.R., M.M. and R.H.; Methodology, M.M.; Resources, A.-G.R.; Software, M.M.; Supervision, A.-G.R.; Visualization, A.-G.R.; Writing—original draft, M.M.; Writing一review \& editing, R.H.

Funding: This research received no external funding.

Conflicts of Interest: The authors declare no conflict of interest.

\section{References}

1. Tetlock, P.E.; Manstead, A.S.R. Impression management versus interpsychic explanations in social psychology: A useful dichotomy? Psychol. Rev. 1985, 92, 59-77. [CrossRef]

2. Bansal, P.; Kistruck, G. Seeing is (not) believing: Managing the impressions of the firm's commitment to the natural environment. J. Bus. Ethics 2006, 67, 165-180. [CrossRef]

3. Meyer, J.W.; Rowan, B. Institutionalized organizations: Formal structure as myth and ceremony. Am. J. Sociol. 1977, 83, 340-363. [CrossRef]

4. Arndt, M.; Bigelow, B. Presenting structural innovation in an institutional environment: Hospitals' use of impression management. Adm. Sci. Q. 2000, 45, 494-522. [CrossRef]

5. Abrahamson, E.; Park, C. Concealment of negative organizational outcomes: An agency theory perspective. Acad. Manag. J. 1994, 37, 1302-1334.

6. Ogden, S.; Clarke, J. Customer disclosures, impression management and the construction of legitimacy: Corporate reports in the UK privatised water industry. Account. Audit. Account. J. 2005, 18, 313-345. [CrossRef]

7. De Villiers, C.; Venter, E.R.; Hsiao, P.C.K. Integrated reporting: Background, measurement issues, approaches and an agenda for future research. Account. Financ. 2017, 57, 937-959. [CrossRef]

8. Othman, S.; Darus, F.; Arshad, R. The influence of coercive isomorphism on corporate social responsibility reporting and reputation. Soc. Responsib. J. 2011, 7, 118-135. [CrossRef]

9. Suchman, M. Managing legitimacy: Strategic and institutional approaches. Acad. Manag. Rev. 1995, 20, 571-610. [CrossRef]

10. Camilleri, M.A. Theoretical insights on integrated reporting: The inclusion of nonfinancial capitals in corporate disclosures. Corp. Commun. Int. J. 2018, 23, 567-581. [CrossRef]

11. Diouf, D.; Boiral, O. The quality of sustainability reports and impression management: A stakeholder perspective. Account. Audit. Account. J. 2017, 30, 643-667. [CrossRef]

12. Tilling, M.V. Some thoughts on legitimacy theory in social and environmental accounting. Soc. Environ. Account. J. 2004, 24, 3-7. [CrossRef]

13. DiMaggio, P.; Powell, W. The iron cage revisited: Institutional isomorphism and collective rationality in organizational fields. Am. Sociol. Rev. 1983, 48, 147-160. [CrossRef]

14. Hofstede, G. Culture's Consequences; Sage Publications: Thousand Oaks, CA, USA, 1980.

15. Gray, S.J. Towards a theory of cultural influence on the development of accounting systems. Abacus 1988, 1-15. [CrossRef]

16. García-Sánchez, I.-M.; Rodríguez-Ariza, L.; Frías-Aceituno, J.-V. The cultural system and integrated reporting. Int. Bus. Rev. 2013, 22, 828-838. [CrossRef]

17. Churet, C.; Eccles, R.G. Integrated reporting, quality of management, and financial performance. J. Appl. Corp. Financ. 2014, 26, 56-64.

18. Păunică, M.; Mocanu, M. Green controlling-Concept and practice. In Proceedings of the 11th International Conference on Business Excellence, Bucharest, Romania, 30-31 March 2017. [CrossRef] 
19. Avram, V.; Calu, D.A.; Dumitru, V.F.; Dumitru, M.; Glăvan, M.E.; Jinga, G. The institutionalization of the consistency and comparability principle in the European Companies. Energies 2018, 11, 3456. [CrossRef]

20. Roman, A.G.; Mocanu, M.; von Ahsen, A. Sustainability reporting. The case of SMEs in the European Union. In Proceedings of the 9th International Conference Accounting and Management Information Systems, Bucharest, Romania, 11-12 June 2014; pp. 465-475.

21. Camodeca, R.; Almici, A.; Sagliaschi, U. Sustainability disclosure in integrated reporting: Does it matter to investors? A cheap talk approach. Sustainability 2018, 10, 4393. [CrossRef]

22. Iamandi, I.E.; Constantin, L.G. Quantifying corporate social responsibility involvement in art and culture projects in Romania and Bulgaria. Proced. Econ. Financ. 2012, 3, 1122-1127. [CrossRef]

23. IIRC. The International <IR> Framework; International Integrated Reporting Council: London, UK, 2013.

24. Dumay, J.; Bernardi, C.; Guthrie, J.; Demartini, P. Integrated reporting: A structured literature review. Account. Forum 2016, 40, 166-185. [CrossRef]

25. Flower, J. The international integrated reporting council: A story of failure. Crit. Perspect. Account. 2015, 27, 1-17. [CrossRef]

26. Brown, J.; Dillard, J. Integrated reporting: On the need for broadening out and opening up accounting. Audit. Account. J. 2014, 27, 1120-1156. [CrossRef]

27. De Villiers, C.; Rinaldi, L.; Unerman, J. Integrated reporting: Insights, gaps and an agenda for future research. Account. Audit. Account. J. 2014, 27, 1042-1067. [CrossRef]

28. Stubbs, W.; Higgins, C. Integrated reporting and internal mechanisms of change. Account. Audit. Account. J. 2014, 27, 1068-1089. [CrossRef]

29. Serafeim, G. Integrated Reporting and investor clientele. J. Appl. Corp. Financ. 2015, 27, 34-51. [CrossRef]

30. Zhou, S.; Simnett, R.; Green, W. Does Integrated Reporting matter to the capital market? Abacus 2016, 53, 94-132. [CrossRef]

31. Perego, P.; Kennedy, S.; Whiteman, G. A lot of icing but little cake: Taking Integrated Reporting forward. J. Clean. Prod. 2016, 136, 53-64. [CrossRef]

32. Velte, P.; Stawinoga, M. Integrated reporting: The current state of empirical research, limitations and future research implications. J. Manag. Control 2017, 28, 275-320. [CrossRef]

33. Melloni, G.; Caglio, A.; Perego, P. Saying more with less? Disclosure conciseness, completeness and balance in Integrated Reports. J. Account. Public Policy 2017, 36, 220-238. [CrossRef]

34. Melloni, G. Intellectual capital disclosure in integrated reporting: An impression management analysis. J. Intellect. Cap. 2015, 16, 661-680. [CrossRef]

35. Melloni, G.; Stacchezzini, R.; Lai, A. The tone of business model disclosure: An impression management analysis of the integrated reports. J. Manag. Gov. 2015, 2, 1-26. [CrossRef]

36. Stacchezzini, R.; Melloni, G.; Lai, A. Sustainability management and reporting: The role of integrated reporting for communicating corporate sustainability management. J. Clean. Prod. 2016, 136, 102-110. [CrossRef]

37. Constantin, S.B. Tax evasion through fictitious economic operations, obstacle to sustainable development. Ann. "Constantin Brâncuşi” Univ. Târgu Jiu Economy Ser. 2016, 3, $26-29$.

38. Integrated Reporting Council of South Africa (IRCSA). Integrated Reporting and the Integrated Report. Discussion Paper. Discussion Paper. 25 January 2011. Available online: www.sustainabilitysa.org (accessed on 25 January 2012).

39. Gaa, J.C. Corporate governance and the responsibility of the board of directors for strategic financial reporting. J. Bus. Ethics 2010, 90, 179-197. [CrossRef]

40. Abeysekera, I. A template for integrated reporting. J. Intellect. Cap. 2013, 14, 227-245. [CrossRef]

41. Popa, A.; Hadad, S.; Păiușan, R.; Năstase, M. A new method for agricultural market share assessment. Sustainability 2019, 11, 88. [CrossRef]

42. Abeysekera, I. Intellectual capital practices of firms and the commodification of labour. Account. Audit. Account. J. 2008, 21, 36-48. [CrossRef]

43. Westley, F.; Mintzberg, H. Visionary leadership and strategic management. Strateg. Manag. J. 1989, 10, 17-32. [CrossRef]

44. Jensen, J.; Berg, N. Determinants of traditional sustainability reporting versus integrated reporting. Inst. Approach Bus. Strategy Environ. 2012, 21, 299-316. [CrossRef] 
45. Integrated Reporting Committee of South Africa (IRCSA). Achieving Balance in the Integrated Report: An Information Paper. 2018. Available online: http://integratedreportingsa.org/ircsa/wp-content/ uploads/2018/12/IRC-Achieving-Balance-Paper-web.pdf (accessed on 24 February 2019).

46. Bernardi, C.; Stark, A.W. Environmental, social and governance disclosure, integrated reporting, and the accuracy of analyst forecasts. Brit. Account. Rev. 2018, 50, 16-31. [CrossRef]

47. Lee, K.W.; Yeo, G.H.H. The association between integrated reporting and firm evaluation. Rev. Quant. Financ. Acc. 2015, 47, 1-30.

48. Jindřichovská, I.; Kubickova, D.; Nulíček, V. Non-financial reporting in Czech beverage industry. In Proceedings of the Non-Financial Reporting in Czech Beverage Industry, Prague, Czech Republic, 11-12 October 2018; pp. 210-218.

49. Davis, A.K.; Tama-Sweet, I. Managers' use of language across alternative disclosure outlets: Earnings press releases versus MD\&A. Contemp. Account. Res. 2012, 29, 804-837. [CrossRef]

50. Clatworthy, M.A.; Jones, M.J. Differential patterns of textual characteristics and company performance in the chairman's statement. Account. Audit. Account. J. 2006, 19, 493-511. [CrossRef]

51. De Franco, G.; Hope, O.-K.; Vyas, D.; Zhou, Y. Analyst report readability. Contemp. Account. Res. 2015, 32, 76-104. [CrossRef]

52. Li, F. Annual report readability, current earnings, and earnings persistence. J. Account. Econ. 2008, 45, 221-247. [CrossRef]

53. Bakar, A.S.A.; Ameer, R. Readability of corporate social responsibility communication in Malaysia. Corp. Soc. Responsib. Environ. Manag. 2011, 18, 50-60. [CrossRef]

54. Cho, C.H.; Roberts, R.W.; Patten, D.M. The language of US corporate environmental disclosure. Acc. Organ. Soc. 2010, 35, 431-443. [CrossRef]

55. Plumlee, M.; Brown, D.; Hayes, R.M.; Marshall, R.S. Voluntary environmental disclosure quality and firm value: Further evidence. J. Account. Public Policy 2015, 34, 336-361. [CrossRef]

56. Wang, M.; Hussainey, K. Voluntary forward-looking statements driven by corporate governance and their value relevance. J. Account. Public Policy 2013, 32, 26-49. [CrossRef]

57. Gibbins, M.; Richardson, A.; Waterhouse, J. The management of corporate financial disclosure: Opportunism, ritualism, policies, and processes. J. Account. Res. 1990, 28, 121-143. [CrossRef]

58. Oliveira, J.; Rodrigues, L.L.; Craig, R. Voluntary risk reporting to enhance institutional and organizational legitimacy, evidence from Portuguese banks. J. Financ. Regul. Compliance 2011, 19, 271-288. [CrossRef]

59. Oliver, C. Strategic responses to institutional processes. Acad. Manag. Rev. 1991, 16, 145-179. [CrossRef]

60. Linsley, P.M.; Shrives, P.J.; Crumpton, M. Risk disclosure: An exploratory study of UK and Canadian banks. J. Bank. Regul. 2006, 7, 268-282. [CrossRef]

61. Hossain, M. The extent of disclosure in annual reports of banking companies: The case of India. Eur. J. Sci. Res. 2008, 23, 659-680.

62. Sanchez-Ballesta, J.P.; Bernal Llorens, M. Monitoring, reputation and accountability in issuing banks in mid-nineteenth-century Spain. Explor. Econ. Hist. 2010, 47, 403-419. [CrossRef]

63. Cohn, M.A.; Mehl, M.R.; Pennebaker, J.W. Linguistic markers of psychological change surrounding September 11, 2001. Psychol. Sci. 2004, 15, 68-93. [CrossRef]

64. Ernstberger, J.; Grüning, M. How do firm- and country-level governance mechanisms affect firms' disclosure? J. Account. Public Policy 2013, 32, 50-67. [CrossRef]

65. Frías-Aceituno, J.V.; Rodríguez-Ariza, L.; García-Sánchez, I.M. Is integrated reporting determined by a country's legal system? An exploratory study. J. Clean. Prod. 2013, 44, 45-55. [CrossRef]

66. Clarkson, P.M.; Li, Y.; Richardson, G.D.; Vasvari, F.P. Revisiting the relation between environmental performance and environmental disclosure: An empirical analysis. Account. Organ. Soc. 2008, 33, 303-327. [CrossRef]

(C) 2019 by the authors. Licensee MDPI, Basel, Switzerland. This article is an open access article distributed under the terms and conditions of the Creative Commons Attribution (CC BY) license (http:/ / creativecommons.org/licenses/by/4.0/). 